LETTER TO THE EDITOR

\title{
Gerodontology: effects of ageing on the oral mucosa
}

\author{
César Rivera ${ }^{1}$, María Jesús Arenas-Márquez²
}

1. César Rivera. Department of Basic Biomedical Sciences, Faculty of Health Sciences, University of Talca (UTALCA), Talca, Chile.

Email: contacto@cesarrivera.cl

2. María Jesús Arenas-Márquez. Gerontology

Program, Faculty of Medical Sciences, University of Campinas (UNICAMP), Campinas, São Paulo, Brazil. Email: arenasmarquez@gmail.com

Correspondencia a: arenasmarquez@gmail.com Trabajo recibido el 20/10/2016. Aprobado para su publicación el 08/02/2017

\section{Mr. Editor.}

Ageing (biological) is characterized by a progressive loss of physiological integrity, leading to functional changes and an increased vulnerability to death ${ }^{1}$. These progressive changes can be observed in the oral mucosa. The aim of this letter - dedicated to geriatric dentistry and specialists in oral medicine- is to summarize the effects of aging in soft oral tissues. The oral mucosa of elderly persons may not be distinguishable from that in young patients. Nevertheless, the continuing trauma (e.g., cheek biting), mucosal manifestations of autoimmune skin diseases, habits (e.g., smoking) and hypofunction of the salivary glands can alter the appearance and character of the oral tissues in elderly persons ${ }^{2}$.

In the epithelium, the major changes recorded are the presence of less prominent epithelial ridges, epithelial atrophy and a reduction of the cellular density and mitotic activity ${ }^{3}$. Along with this, there is a loss of elastin and adipose tissue in the submucosa and an increase in fibrous connective tissue with a degenerative change in the collagen. All this can result in the slowing of tissue regeneration, which should be taken into consideration when installing dental implants.

Normal ageing causes a loss of sense of taste due to changes in the membranes of the gustatory cells, which alter the function of ionic canals and receptors ${ }^{4}$.

Clinically, the histological changes may be accompanied by dry thin smooth oral mucosal surfaces, with a loss of elasticity and a characteristic stippling. These changes could predispose the oral territories to trauma and infection, particularly when the patients are using dental prosthesis or are afflicted by disturbances in salivary function (e.g., chronic hyposialia) $)^{5}$. Ectopic sebaceous glands (Fordyce spots) in the lips and cheeks can also increase with advancing age. Dorsum of the tongue shows a decrease in the filiform papillae, which gives it a smooth and shiny appearance ${ }^{6}$. This appearance could be exacerbated by the deficit of iron or B complex vitamins. The ventral zone of the tongue develops sublingual varicosities, which are considered variations from normal ${ }^{7}$.

Recently we carried out a systematic review of literature to identify major lesions of the oral mucosa in older persons. The data received from thirteen countries showed that some of the more relevant diagnosis in elderly persons are denture-related stomatitis, epulis fissuratum, traumatic ulcers, irritation fibroma, recurring aphthous stomatitis, fissured tongue, hemangioma, melanin pigmentations and oral lichen planus ${ }^{8}$.

The changes in the oral mucosa which occur frequently during the ageing process are related to the subtle changes in the lining of the buccal structures. The knowledge of these changes and to know what to look for in the mouth of the elderly persons is the first step to guaranteeing oral health during the ageing process and providing good services in the context of geriatric dentistry.

\section{ETHICAL DISCLOSURES}

Protection of human and animal subjects. The authors declare that no experiments were performed on humans or animals for this study.

Confidentiality of data. The authors declare that no patient data appear in this article.

Right to privacy and informed consent. The authors declare that no patient data appear in this article.

Absence of any conflict of interest.

\section{References}

1. Lopez-Otin C, Blasco MA, Partridge L, Serrano M, Kroemer G. The hallmarks of aging. Cell. 2013;153(6):1194-217. DOI: 10.1016/j.cell.2013.05.039.

2. De Rossi SS, Slaughter YA. Oral changes in older patients: a clinician's guide. Quintessence Int. 2007;38(9):773-80.

3. Abu Eid R, Sawair F, Landini G, Saku T. Age and the architecture of oral mucosa. Age (Dordr). 2012;34(3):651-8. DOI: 10.1007/s11357-011-9261-1.

4. Boyce JM, Shone GR. Effects of ageing on smell and taste. Postgrad Med J. 2006;82(966):239-41.

5. Guiglia R, Musciotto A, Compilato D, Procaccini M, Lo Russo L, Ciavarella D, et al. Aging and oral health: effects in hard and soft tissues. Curr Pharm Des. 2010;16(6):619-30.

6. Lamster IB, Northridge ME (Eds.). Improving Oral Health for the Elderly: An Interdisciplinary Approach. $1^{\text {a }}$ ed. New York: Springer; 2008.

7. Rivera C, Droguett D, Arenas-Márquez MJ. Oral mucosal lesions in a Chilean elderly population: A retrospective study with a systematic review from thirteen countries. J Clin Exp Dent. 2017;9(2):e276-e283. DOI: $10.4317 /$ jced.53427.

8. Rivera C. Mucosa oral: alteraciones y variaciones en 100 palabras (eBook). Mouth. 2016;1(1):eb04102016es. DOI: 10.5281/zenodo.159298. 